\title{
A responsabilidade civil contratual na prestação de cuidados de saúde em Portugal e Macau
}

\author{
Contractual medical liability in Portugal and Macao
}

La responsabilidad civil contractual por servicios sanitarios en Portugal y Macao

Rui Miguel Prista Patrício Cascão ${ }^{1}$

RESUMO: A responsabilidade civil contratual do prestador de cuidados de saúde é uma via possível, em Portugal e em Macau, para o ressarcimento de danos sofridos em virtude de uma prestação defeituosa de cuidados de saúde. No entanto, algumas limitações de ordem legislativa, jurisprudencial e doutrinária levam a uma relativa incerteza na aplicação deste modelo. Este artigo procura reduzir a incerteza, sugerindo um paradigma interpretativo claro e recomendando alterações legislativas.

Palavras-chave: Responsabilidade Civil. Contrato. Dano Médico.

ABSTRACT: Liability of healthcare providers can be framed under the theory of contract in the law of Portugal and Macao, to obtain compensation for injury suffered by aggrieved patients, as a result of medical adverse events. However, shortcomings in the law, court practice and literature lead to some uncertainty in adjudication. This article aims at reducing said uncertainty, setting forward a clear-cut adjudication paradigm, while recommending legal reform.

Keywords: Liability. Contract. Medical Treatment Injury.

RESUMEN: La responsabilidad civil del prestador de servicios sanitarios es una forma posible, en Portugal así como en Macao, para obtener el resarcimiento de daños sufridos en virtud de una prestación defectuosa de servicios sanitarios. Todavía, salen de relieve algunas limitaciones de este modelo, en el plano legislativo, jurisprudencial y doctrinario, que conducen a una relativa incerteza en su aplicación. Este artigo tiene por objetivo reducir la incerteza, proponiendo un paradigma de interpretación claro, mientras recomendando revisión legislativa.

Palabras-Ilave: Responsabilidad Civil. Contrato. Daño Médico.

\footnotetext{
${ }^{1}$ Licenciado em Direito (Coimbra, Portugal), Doutor em Direito (Tilburg, Países Baixos). Assessor Jurídico da Direcção de Serviços de Assuntos da Justiça do Governo da Região Administrativa Especial de Macau da República Popular da China. Investigador Principal do Instituto Jurídico/Centro de Direito Biomédico da Faculdade de Direito da Universidade de Coimbra, Portugal. Membro fundador e membro do Conselho de Governadores da ALDIS-Associação Lusófona de Direito da Saúde.
}

Email: rui.cascao@gmail.com 


\section{Introdução}

Na aurora da civilização, prescrevia já o Código de Hammurabi, uma das primeiras codificações da história do direito, datando de cerca de 1754 AEC, no seu parágrafo 215, que "se um médico fizer uma incisão com um bisturi e curar o paciente, receberá dez shekels em dinheiro". Se da incisão feita pelo médico decorresse a morte do paciente, as suas mãos seriam cortadas.

Como é evidente, em tempos tão recuados, o instituto jurídico do contrato não se encontrava ainda destrinçado do da responsabilidade civil extracontratual e criminal. Avançando vários séculos, a responsabilidade civil contratual do prestador de cuidados de saúde foi expressamente consagrada em 1936 pela Cour de cassassion, o supremo tribunal francês. No seu eloquente aresto de 20 de maio de 1936 (Arrêt Mercier), decidiu este areópago que:

considerando que se forma, entre o médico e o seu cliente um verdadeiro contrato, o qual comporta para o médico um dever, obviamente não de curar o paciente, mas pelo menos de lhe prestar cuidados de saúde conscientes, atenciosos e conformes a estado actual da ciência; (...) a violação, ainda que involuntária, desta obrigação contratual, é sancionada por uma responsabilidade da mesma natureza, ou seja, contratual".

A cour de cassassion afirmou, neste douto acórdão, a doutrina do insigne jurisconsulto francês Demogue, que defendera ser de natureza contratual a responsabilidade civil do prestador de cuidados de saúde. Segundo a doutrina de Demogue, acolhida pelo aresto referido e pela jurisprudência constante dos tribunais superiores franceses, este tipo de contrato envolveria, não uma obrigação de resultado (obligation de résultat), cujo conteúdo consistiria em atingir a cura do paciente, em que o devedor apenas se poderia, uma vez que a culpa do incumprimento é presumida, eximir mediante a invocação de caso fortuito ou causa de força maior, mas apenas uma obrigação de meios (obligation de moyens), cujo conteúdo seria o de prestar cuidados de saúde diligentes, de acordo com as leges artis, afastando-se a presunção de culpa do incumprimento do contrato (1).

Segundo Hondius e Van Hooft,

a opção contratual tem como vantagem significativa o facto de o contrato se basear na autonomia contratual das partes. Ora, este é o habitat natural 
para os direitos do paciente, designadamente o direito a ser informado, o direito a consentir e o direito de acesso ao seu dossier clínico (2).

Nestes termos, procuraremos neste estudo proceder, com enfoque juscomparatístico, à análise da responsabilidade civil contratual do prestador de cuidados de saúde no ordenamento jurídico de Portugal e da Região Administrativa Especial de Macau da República Popular da China (doravante abreviada como Macau), sistema de matriz portuguesa $^{2}$, no que se refere à sua relevância na adjudicação de litígios, procurando apresentar, como conclusão, um paradigma interpretativo persuasivo no contexto do ordenamento jurídico de Portugal e de Macau.

\section{Natureza jurídica}

Em Portugal, o enquadramento contratualista da relação médico-paciente já é reconhecido pela doutrina desde 1972 por Moitinho de Almeida, pelo menos no contexto da prestação de cuidados de saúde por privados (3), (4). Um contrato de prestação de serviço é, segundo o disposto no Artigo $1154 .^{\circ}$ do Código Civil (CC), o contrato "em que uma das partes se obriga a proporcionar a outro certo resultado do seu trabalho intelectual ou manual, com ou sem retribuição".

O contrato de prestação de serviço pode, nos termos do Artigo 1155. CC, revestir uma das seguintes modalidades: mandato (artigo 1157. e ss. CC), empreitada (artigo 1207. ss. CC) ou depósito (artigo 1185. ss. CC). O mandato é, de acordo com o Artigo $1157 .^{\circ} \mathrm{CC}$, "o contrato pelo qual uma das partes se obriga a praticar um ou mais actos jurídicos por conta da outra". Por outro lado, a empreitada é, nos termos do Artigo $1207 .{ }^{\circ}$ CC, o contrato pelo qual uma das partes se obriga em relação à outra a realizar certa obra, mediante um preço ${ }^{3}$.

A abrangência do contrato de empreitada é controvertida no direito português. É, neste contexto, oportuno referir a célebre controvérsia da década de 80 , na sequência do Acórdão do Supremo Tribunal de Justiça de 3 de novembro de $1983^{4}$, o qual qualificou

\footnotetext{
2 Dadas as grandes semelhanças, ao presente, do regime jurídico aplicável na matéria em apreço, não faremos referência específica ao direito de Macau, salvo quando o regime jurídico seja aí manifestamente diferente.

${ }^{3}$ Não nos referiremos ao contrato de depósito, por esta modalidade do contrato de prestação de serviço não ser útil para a determinação da natureza jurídica do contrato de prestação de cuidados de saúde.

${ }^{4}$ Boletim do Ministério da Justiça, n. -331 , p. 489 ss.
} 
uma prestação de serviço de obra intelectual como contrato de empreitada. O referido acórdão foi apoiado por Ferrer Correia e Henrique Mesquita (tese do conceito amplo de obra), mas criticado por Antunes Varela (tese do conceito restrito de obra) ${ }^{5}$. Desde o Acórdão do STJ de 2 de fevereiro de $1988^{6}$, vem sendo pacífica na jurisprudência portuguesa a opção pelo conceito restrito de obra, excluindo do âmbito do contrato de empreitada a obra de natureza intelectual e qualificando tais contratos como contratos de prestação de serviço inominados. Nestes termos, o contrato de prestação de cuidados de saúde deve ser qualificado como contrato de prestação de serviço inominado (sui generis), seguindo a disciplina do Artigo 1157. e seguintes do Código Civil, com as devidas adaptações, por remissão do Artigo 1156.ำ do mesmo diploma (3) (4).

Na Região Administrativa Especial de Macau da República Popular da China, o entendimento é o mesmo (Art. 1080. e seguintes do Código Civil de Macau) ${ }^{7}$.

No entanto, em alguns ordenamentos jurídicos, a empreitada abrange todas as prestações de serviços - França, Bélgica (5) (6) ${ }^{8}$; noutros há divergências sérias na doutrina e na jurisprudência sobre se a empreitada abrange ou não todas as prestações de serviços - Áustria, Grécia (5).

Se bem que, em vários ordenamentos jurídicos, o contrato de prestação de cuidados de saúde é um contrato inominado, noutros ordenamentos jurídicos, como é o caso dos Países Baixos (em 1994) ou da Alemanha (em 2013) ${ }^{9}$, o legislador, de forma a acompanhar a profunda terciarização da economia, optou por consagrar legislativamente contratos nominados de prestação de cuidados de saúde. A esta modernização da disciplina jurídica dos contratos, consagrando uma modalidade nominada de contrato de prestação de cuidados de saúde, não terá sido alheio o facto de se tratarem de países em que o sistema de saúde é baseado no modelo Bismarck (prestadores de cuidados de

\footnotetext{
${ }^{5}$ Revista da Ordem dos Advogados, Ano 45, Abril de 1985, p. 133 ss.

${ }^{6}$ Boletim do Ministério da Justiça, n.․ 374, p.449.

7 Acórdão de Uniformização de Jurisprudência, de 18 de Janeiro de 2006, Processo n.ำ 23/2005.

8 Refira-se no entanto que, em França, o regime contratualista vigente no sector privado convergiu profundamente com o da responsabilidade civil extracontratual por actos de gestão pública em matéria de responsabilidade civil médica desde a Loi du 4 mars 2002 relative aux droits des malades et à la qualité du système de santé.

${ }^{9}$ Antes da codificação, era praticamente unânime a qualificação deste contrato como contrato de prestação de serviços (Dienstvertrag): BGHZ 63,306,309 = NJW 1975,305; BGHZ 76, 249, 261 = NJW 1980, 1452, 1453; BGH NJW 1981,613; BGH NJW 1981, 2002; BGHZ 97, 273; Laufs/Uhlenbrück, Handbuch des Arztrechts, 1999 (2), §39; Staudinger/Richardi anotação ao §611 ss. BGB; Palandt/Putzo, anotação ao §611 BGB; Soergel, anotação ao §631 BGB in Münchener Kommentar.
} 
saúde privados e/ou públicos, mas, neste caso, praticando actos de gestão privada; carácter privado e/ou mutualista do seguro de saúde dos cidadãos), contrastando com o modelo Beveridge (sistema nacional de saúde público universal e tendencialmente gratuito, financiado pelo orçamento geral do estado) (4) (8).

Finalmente, refira-se que o enquadramento da relação médico-paciente é de escassa ou nula relevância em alguns ordenamentos jurídicos. Este é o caso designadamente dos países de tradição anglo-saxónica (e.g. Inglaterra e País de Gales, Estados Unidos da América, Canadá, Austrália), uma vez que na common law só excepcionalmente é indenizado o dano não patrimonial em sede de responsabilidade civil contratual e ainda porque o critério de aferição da responsabilidade civil seria o mesmo da responsabilidade extracontratual (tort of negligence; breach of duty of care) (9), (10); é ainda o caso dos ordenamentos jurídicos em que o dano médico é ressarcido através de mecanismos de seguro no-fault (Suécia, Finlândia, Dinamarca, Noruega, Islândia e Nova Zelândia) (11) (12) (13).

\section{O conteúdo do contrato}

Num contrato de prestação de cuidados de saúde, as partes principais são o paciente e o prestador de cuidados de saúde. Este será o caso típico de um paciente que consulta um médico profissional liberal no seu consultório.

No entanto, casos haverá em que existem outras partes contratuais, designadamente quando o responsável pelo pagamento do preço contratual é uma seguradora, ou ainda nos casos em que o paciente tem um contrato com uma seguradora de saúde, a qual tem um contrato com um médico convencionado (Kassenpatient). Nestas circunstâncias, poderá haver dúvidas sobre a existência de uma verdadeira relação contratual entre o paciente e o prestador de cuidados de saúde, aporia que poderá ser resolvida através do recurso ao regime do contrato a favor de terceiro (Artigo 443. e seguintes do Código Civil) ${ }^{10}$, ou à figura das relações contratuais de facto (14).

Semelhante é a situação de uma pessoa sem capacidade de exercício, como por exemplo os menores e os interditos, bem como as pessoas que estejam temporariamente incapacitadas de fazer uma declaração negocial (por exemplo, em caso de emergência).

${ }^{10} \mathrm{Em}$ Macau, Artigo 437. e seguintes do Código Civil. 
Nestes casos, a declaração negocial do incapaz poderá ser suprida por quem detenha responsabilidades parentais ou tutelares (4).

Nos ordenamentos jurídicos em que se procedeu à codificação desta modalidade contratual, existem normas específicas para resolver estas situações em que não existe prima facie uma eficácia relativa do contrato ou em que o paciente é incapaz de contratar. Assim, no Código Civil (Burgerlijk Wetboek) neerlandês estes aspectos são resolvidos pelos artigos 7:461, 7:465 e 7:466; na Alemanha pelo § 630a I in fine.

Há vários deveres cuja violação pode desencadear a responsabilidade civil contratual do prestador de cuidados de saúde. Este é, em primeira linha o caso do dever de diligência, ou seja, o dever de o prestador de cuidados de saúde os prestar de forma consciente, com o respeito pelas regras de conduta profissional, segundo as normas e os protocolos comummente aceites na sua especialidade, de acordo com o estado actual da ciência e com as circunstâncias concretas em que presta os cuidados de saúde (leges artis ad hoc). Esta será a bitola de aferição da qualidade do tratamento médico e, consequentemente a (i) licitude (e, como veremos adiante, tendencialmente, da culpa) que poderá desencadear a responsabilização do prestador de cuidados de saúde.

De enorme relevância nesta matéria reveste o dever de o prestador de cuidados de saúde informar o paciente e de dele obter o seu consentimento esclarecido. 0 consentimento deve ser prestado pessoalmente ao paciente e apenas ao paciente, salvo em caso de constituição de procurador para cuidados de saúde, o exercício residual, por parte do médico, do "privilégio terapêutico" (caso o esclarecimento seja idóneo a causar lesão mortal ou grave à integridade física do paciente) ou ainda no direito do paciente a não ser informado. O paciente deve ser informado sobre o seu estado de saúde, sobre a natureza dos métodos de diagnóstico ou terapia propostos pelo prestador de cuidados de saúde, sobre os seus potenciais riscos, benefícios e efeitos secundários, sobre as alternativas ao tratamento proposto, bem como a prognose e as consequências previsíveis da ausência de tratamento. A informação deve ser prestada ao paciente de forma a que ele possa entender a informação que Ihe é transmitida e, assim, exercer, de forma esclarecida, a sua autonomia, fazendo uma escolha informada, consentindo no acto 


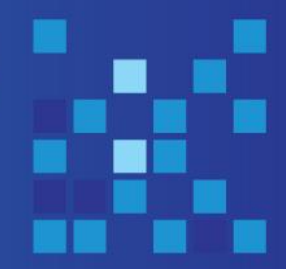

médico; o seu consentimento é sempre retratável (5) ${ }^{11}$. A violação do dever de informação pode desencadear a responsabilidade civil do prestador de cuidados de saúde, independentemente de o dever de diligência (leges artis) ter sido impecavelmente cumprido, quando o paciente sofra danos e tivera uma escolha de terapêutica alternativa (4) Esta "válvula de escape", que visa suprir a relativa dificuldade de acesso, por parte dos pacientes lesados, à indemnização dos seus danos é frequentemente criticada por alguns autores, como Lambert-Faivre, que o considera como "um falso alibi para indemnizar um evento médico adverso" ou Hellner, no sentido que "é muito raro um paciente alegar a violação do dever de informação se efectivamente tudo correu bem" (4) (6) (15).

De significativa importância é ainda o dever de documentação: o prestador de cuidados de saúde tem o dever de registar meticulosamente no dossier clínico todos os factos relevantes relacionados com a prestação dos cuidados de saúde no dossier clínico. A inexistência do dossier clínico, bem quaisquer insuficiências de que padeça, poderão ter um impacte processual negativo para o prestador de cuidados de saúde em sede de acção de responsabilidade civil, como explanaremos adiante ${ }^{12}$.

\section{Responsabilidade civil contratual por dano médico}

Quanto ao regime de responsabilidade civil por incumprimento do prestador de cuidados de saúde, quando este cause dano iatrogénico, i.e., causado por (ou omissão de) um acto médico, o princípio básico é o de que o devedor que falta culposamente ao cumprimento da obrigação se torna responsável pelo prejuízo causado ao credor, nos termos do Artigo $798 \mathrm{CC}$, incumbindo ao devedor provar que a falta de cumprimento ou o cumprimento defeituoso da obrigação não procede de culpa sua, apreciando-se a culpa nos termos aplicáveis à responsabilidade civil (Artigo 799 CC).

$\mathrm{Na}$ modalidade de empreitada, o Artigo 1208 prescreve que "o empreiteiro deve executar a obra em conformidade com o que foi convencionado, e sem vícios que excluam ou reduzam o valor dela, ou a sua aptidão para o uso ordinário ou previsto no contrato". A

\footnotetext{
${ }^{11}$ Artigos 5. a 9. da Convenção de Oviedo sobre direitos humanos e biomedicina de Oviedo, de 4 de Abril de 1997; Artigo 19. a 25.. do Regulamento n.ำ 707/2016 da Ordem dos Médicos (Regulamento de Deontologia Médica); Norma da Direcção Geral de Saúde 015/2013 de 03/10/2013; §630c-630e BGB (Alemanha); 7:448-7:451 BW (Países Baixos).

12 Artigo 39ㅇ a 44. do Regulamento n. 707/2016 da Ordem dos Médicos (Regulamento de Deontologia Médica); §630f-630g BGB (Alemanha); 7:454-7:456 BW (Países Baixos);
} 
empreitada, tal como a compra e venda, estabelece para o empreiteiro (tal como para o vendedor), uma obrigação de resultado ${ }^{13}$, ou seja, o prestador de serviços tem que atingir um determinado efeito útil previsto no contrato, uma certa e necessária consecução ou obtenção de um determinado objetivo, interesse ou resultado. Nestes termos, provado o defeito da obra (falta de conformidade) pelo credor, o empreiteiro só ficará exonerado em caso de impossibilidade objectiva e não culposa, nos termos do Artigo 790. CC (16).

Por outro lado, no mandato e na prestação de serviços inominada, na qual se subsume, no direito português e macaense, o contrato de prestação de cuidados de saúde, estará normalmente em causa uma obrigação de meios, na qual o mandatário ou o prestador de serviços apenas se comprometem a desenvolver prudente e diligentemente certa actividade para a obtenção de um determinado efeito, sem, todavia, assegurar que o mesmo se produza (16)

Segundo a tendência geral, mas não uniforme, da jurisprudência dos Tribunais Superiores em Portugal ${ }^{14}$, bem como na jurisprudência do Tribunal de Segunda Instância

\footnotetext{
${ }^{13}$ A distinção entre obrigações de meios e obrigações de resultado (obligations de moyens et obligations de résultat) é atribuída ao insigne jurista francês René Demogue (Demogue R. Traité des obligations en Général, vol l. tome V, Paris: Librairie Arthur Rousseau, 1925, p. 536 ss.), considerando-se que, no caso de uma obrigação de meios, a presunção de culpa do devedor se encontra completamente afastada. Este cânone foi consagrado jurisprudencialmente pelo célebre aresto da Cour de cassation (Supremo Tribunal francês) de 20 maio de 1936, arrêt Mercier, D. 1936.I.88.), no contexto de um contrato de prestação de serviços de saúde. Desde então, é jurisprudência firme e constante da Cour de Cassassion que, em caso de obrigação de meios, a presunção de culpa do devedor é afastada. A distinção foi adoptada noutros ordenamentos jurídicos, sendo empregue, por exemplo, nos Países Baixos, (inspanningsverbintenis, resultaatsverbintenis), na Alemanha (Erfolgsverbindlichkeiten, Sorgfaltsverbindlichkeiten), em Itália (obbligazioni di mezzi, obbligazini di risultato), ou em Espanha (obligaciones de medios, obligaciones de resultado): Pinna, A. The Obligations to Inform and to Advise: A Contribution to the Development of European Contract Law. Haia: Boom Juridische Uitgevers, 2003, p.62; Refira-se ainda que em alguns ordenamentos jurídicos, como é o caso dos Países Baixos, em matéria de responsabilidade civil médica, o ónus da prova se encontra superado, existindo um dever mútuo de cooperação das partes para a descoberta da verdade material, sem pontos de partida rígidos quanto à distribuição do ónus da prova: Giesen, I. Bewijslastverdeling, de informatieplicht van de arts en het recht op zelfbeschikking: communicerende vaten! Ars AEqui 45 (1996) 9.

${ }^{14}$ No sentido que defendemos, segundo o qual a presunção de culpa é de escassa importância em caso de obrigação de meios, competindo o ónus da prova da violação das leges artis ao paciente: Acórdãos do STJ de 22/05/2003, Rev. 912/03 (7. ${ }^{a}$ secção); 18/09/2007, Rev. 2334/07 (7. ${ }^{a}$ secção); 15/10/2009, Rev. 1800/08

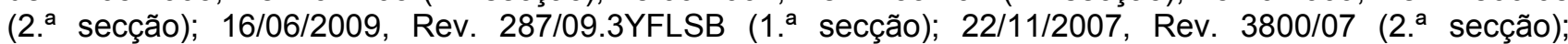
02/10/2008, Rev. 2654/08 (7. a secção); 24/05/2011, Rev. 1347/04.2TBPNF.P1.S1 (1. ${ }^{a}$ secção); 13/09/2011,

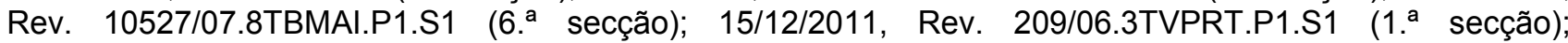
15/11/2012, Rev. 117/2000.L1.S1 (2. ${ }^{a}$ secção); 11/06/2013, Rev. 544/10.6TBSTS.P1.S1 (6. ${ }^{a}$ secção). No sentido contrário, invertendo o ónus da prova da violação das leges artis para o prestador de cuidados de saúde: Acórdãos do STJ de 18/05/2006, rev. 1279/06 (7. a secção); 12/12/2002, Rev. 4057/02 (2.. secção) e

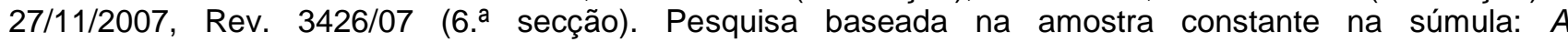
responsabilidade civil por acto médico na jurisprudência das secções cíveis do Supremo Tribunal de Justiça (Sumários de acórdãos de 1996 a Julho de 2014), Supremo Tribunal de Justiça (Portugal).
} 
de Macau $^{15}$, a presunção de culpa imposta pelo Artigo 799./1 do CC Português (idêntico ao Artigo 788.\%/1 do CC de Macau) é fortemente mitigada no contexto de uma obrigação de meios: em caso de acção de indemnização por dano iatrogénico, o paciente tem o ónus da prova do incumprimento por parte do prestador de cuidados de saúde do seu dever de diligência, o qual é aferido de acordo com a diligência normal de um bonus paterfamilias, ou, no caso de um profissional de saúde, de acordo com as regras da arte da sua profissão, de acordo com as circunstâncias (leges artis ad hoc) ${ }^{16}$.

Só após a prova pelo paciente da falta de diligência do prestador de cuidados de saúde (ilicitude), do dano e do nexo de causalidade, funciona a presunção de culpa. Nestes termos, salvo respeito por melhor opinião, que é muitíssimo, perante uma obrigação de meios, o prestador de cuidados de saúde exonera-se da responsabilidade em caso de impossibilidade objectiva ou subjectiva que não lhe seja imputável (16). Na prática, o critério de aferição da ilicitude (violação do dever de diligência) coincide no essencial com o critério da aferição de culpa a título de negligência, em que:

a censura do devedor funda-se apenas em ele não ter agido com a diligência ou com o discernimento exigíveis para ter evitado a falta de cumprimento da obrigação, ou para a ter previsto e evitado, quando porventura nem sequer dela se tenha apercebido (17).

Pelo que, na prática, a presunção de culpa raramente se revelará útil ao paciente, fora no que se refere ao não cumprimento por causa que não seja imputável ao devedor (18) Na prática, apesar de haver divergências na doutrina e na jurisprudência, a diferença fundamental entre o regime da responsabilidade civil contratual e a extracontratual serão, segundo a tendência geral da jurisprudência dos tribunais superiores, essencialmente os mesmos, salvo no que se refere aos prazos de prescrição: três anos na responsabilidade civil extracontratual (artigo 498 Código Civil) e o prazo ordinário da prescrição de vinte anos na responsabilidade civil contratual (artigo 309. ${ }^{\circ}$ Código civil) ${ }^{17}$.

Seguindo a posição de Dias Pereira (4), o ónus da prova deverá flutuar para o prestador de cuidados de saúde apenas naqueles casos em que o paciente tenha que

15 Acórdãos do TSI de 10 de Novembro de 2011, Processo n.ำ 125/2009 (Recurso Cível); TSI de 17 de Janeiro de 2013, Processo ํo 218/2011, TSI de 21 de Fevereiro de 2013, Processo n.. 778/2011.

${ }^{16}$ Encontra-se ainda onerado com a prova do dano e do nexo de causalidade entre o dano e o cumprimento defeituoso.

${ }^{17}$ Acórdão da Relação de Coimbra de 10/02/2007, Processo 2502/05.3TBCBR.C1 
fazer a prova de factos impeditivos ou extintivos do seu direito e não dos factos constitutivos (artigo 342../2 do Código Civil), recorrendo-se à inversão do ónus da prova previsto no artigo 344.. do mesmo diploma ou a presunções judiciais simples ou de experiência, nos termos do artigo 349. do Código Civil. Este será designadamente o caso do ónus da prova do consentimento informado ou em caso de inexistência ou insuficiência do dossier clínico, cujo acervo probatório se encontra na esfera de controlo do prestador de cuidados de saúde e faria o paciente incorrer na probatio diabólica de facto negativo (19).

Refira-se ainda que, no direito português e de Macau, independente de ser adoptada a teoria do cúmulo ou a doutrina da consumpção entre a responsabilidade contratual e extracontratual, o paciente pode ancorar a sua pretensão em ambos os regimes (20).

Outro aspecto que deve ser referido é que, porquanto o enquadramento contratualista é aceitável, sem quaisquer reservas, na relação entre um paciente e um prestador de cuidados de saúde privado, tal não será necessariamente o caso se o prestador de cuidados de saúde tiver natureza pública ou privada no uso de poderes de direito público. Nestas circunstâncias, de acordo com a doutrina e jurisprudência tradicionais em Portugal, segundo o (revogado) Decreto-Lei no 48051 de 21/11/1967, relativo à responsabilidade civil extracontratual do Estado e demais pessoas colectivas públicas no domínio dos actos de gestão pública, a prestação de cuidados de saúde em estabelecimento público no âmbito do sistema nacional de saúde (SNS) tem natureza exclusivamente extracontratual, seguindo o modelo francês; a prestação de cuidados de saúde a utentes do SNS é considerada como acto de gestão pública, sendo a justiça administrativa competente para julgar os litígios relacionados com a responsabilidade civil médica daí adveniente (4) (21) (22).

Em Macau, de acordo com a jurisprudência obrigatória do Tribunal de Última Instância da Região Administrativa Especial de Macau, a responsabilidade civil por dano iatrogénico no contexto da prestação de cuidados de saúde a utentes dos Serviços de Saúde de Macau reveste natureza exclusivamente extracontratual, sendo os litígios exclusivamente dirimidos pela justiça administrativa ${ }^{18}$.

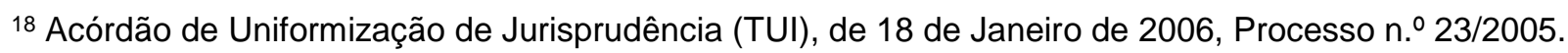


No entanto, alguma jurisprudência recente em Portugal, designadamente o Acórdão do Tribunal Central Administrativo do Norte, de 30 de novembro de 2012, contestou a natureza de acto de gestão pública da prestação de cuidados de saúde nos hospitais públicos, afirmando tratar-se, à luz da vigente Lei n.․ 67/2007, de 31 de dezembro (regime da responsabilidade civil extracontratual do estado e demais entidades públicas), verdadeiramente de um acto de gestão privada e afirmando a existência de uma relação de natureza contratual entre o paciente e o prestador de cuidados de saúde público (23) ${ }^{19}$. A referida decisão foi posteriormente anulada pelo Supremo Tribunal Administrativo, em via de recurso, pelo Acórdão de 16 de janeiro de 2014, por unanimidade. O douto aresto reafirmou a jurisprudência tradicional, infirmando a susceptibilidade de a prestação de cuidados de saúde em estabelecimentos integrados no Sistema Nacional de Saúde poderem ser enquadrados no paradigma contratual, sendo exclusivamente aplicável o regime da responsabilidade civil extracontratual do Estado e demais entes públicos por actos de gestão pública ${ }^{20}$.

A Oriente, refira-se que, em Macau, se encontra em discussão na especialidade, na 3. a Comissão Permanente da Assembleia Legislativa, da Proposta de Lei do Regime Jurídico do Erro Médico, o qual, apesar de omisso quanto à figura do contrato, prevê no seu artigo 27.. a transição do tribunal administrativo para o tribunal judicial de base dos litígios relacionados com a responsabilidade civil dos prestadores de saúde, independentemente da sua natureza pública ou privada; entrando em vigor esta norma, poderá haver maior latitude para o desenvolvimento, em Macau, da responsabilidade civil contratual do prestador de cuidados de saúde.

\section{Conclusão}

O paradigma contratual poderá afigurar-se, prima facie, como uma via menos obstruída para um paciente ser indemnizado pelo dano iatrogénico sofrido em virtude da prestação defeituosa de cuidados de saúde. No entanto, apesar de apresentar vantagens no que se refere à qualidade da relação médico-paciente e quanto à liberdade de escolha do acto médico, o contrato de prestação de cuidados de saúde está longe de ser a

\footnotetext{
${ }^{19}$ Acórdão do tribunal central Administrativo do Norte, de 30 de Novembro de 2012.

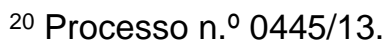


panaceia milagrosa para o ressarcimento expedito e alargado dos danos sofridos pelos pacientes.

No entanto, conforme explanámos, a maior vantagem para um paciente lesado será principalmente a de um prazo de prescrição significativamente maior, vinte anos e não apenas três. Todavia, a presunção de culpa na responsabilidade ínsita no artigo $799 .{ }^{\circ}$ do Código Civil tem face de Jano: porquanto na nossa opinião e da doutrina e jurisprudência dominantes em Portugal e Macau, é fortemente mitigada a ponto de ser praticamente irrelevante por a prestação de cuidados de saúde se tratar, salvo casos excepcionais, de uma obrigação de meios (conceito importado do direito francês e domesticamente descaracterizado), para uma corrente minoritária (mas significativa) da doutrina e jurisprudência, o ónus da prova da ausência de culpa (incluindo o ónus da prova de ter actuado com o dever de diligência esperado segundo as leges artis) flutua para o prestador de cuidados de saúde.

No estado actual da doutrina e da jurisprudência, a responsabilidade civil contratual do prestador de cuidados de saúde mais aparenta ter o potencial da caixa de Pandora de todas as incertezas, combinado com a damages lottery a que se referia Atiyah (24). De forma a salvaguardar a certeza na aplicaçãodo direito, impõe-se uma regra clara, jurisprudencial ou legislativa, para a adjudicação da responsabilidade civil contratual em matéria de dano médico.

Uma solução viável poderá basear-se na elegante norma constante do $\S 630 \mathrm{~h}$ do Código Civil alemão para a distribuição do ónus da prova em matéria de responsabilidade civil contratual do prestador de cuidados de saúde, obtida da decantação dos sedimentos de décadas de soluções doutrinárias e jurisprudenciais:

- por defeito, o ónus da prova da culpa (que equivale à violação do dever de diligência), do dano e da causalidade compete ao paciente lesado;

- presume-se a culpa do prestador de cuidados de saúde nos casos em que se materialize um risco por ele totalmente controlável- voll beherrschbare Risiken- (e.g. infecções nosocomiais, falha de instrumentos);

- o prestador de cuidados de saúde tem o ónus da prova relativamente ao cumprimento do dever de informação ao paciente e quanto às circunstâncias relacionadas com o seu consentimento (fehlende Aufklärung oder Einwilligung); 
- em caso de insuficiência do dossier clínico que permitisse provar um facto alegado pelo paciente em sede de litígio, esse facto presume-se provado (Dokumentationsmängel);

- caso um prestador de cuidados de saúde não esteja habilitado para a prestação de um determinado acto médico, presume-se a causalidade entre a sua actuação e o dano sofrido pelo paciente (fehlende Befähigung);

- em caso de negligência grosseira, presume-se o nexo de causalidade entre a negligência e o dano sofrido pelo paciente (grober Behandlungsfehler).

Como conclusão final, seria interessante salientar a necessidade de reforma profunda do Código Civil português, nos seus 50 anos de maturidade, no que se refere aos contratos de prestação de serviços, criando uma disciplina jurídica inovadora desses contratos, adaptada à actual economia terciária e globalizada, distinguindo-se claramente entre: 1) os contratos de prestação de serviços que consistem na construção, processamento ou alienação de um bem corpóreo e tangível (empreitada), os quais normalmente envolvem obrigações de conformidade do serviço com o contrato (na acepção da Directiva 1999/44/EC ou da Convenção de Viena de 1980 sobre Compra e Venda Internacional de Mercadorias-CISG) e 2) os contratos de prestação de serviços de natureza intelectual, como aquele em apreço, que envolvem obrigações de diligência.

A presunção de culpa do devedor contratual, ínsita no artigo 799 do Código Civil, não pode, nem deve ser, citando J.R.R. Tolkien: one ring to rule them all.

\section{Referências}

1. Demogue, R. Traité des obligations en général, vol. I, Tome V. Paris: Librairie Arthur Rousseau, 1925.

2. Hondius E, van Hooft A. The new Dutch law on medical services. Netherlands International Law Review. XLIII: 1-17, 1996.

3. Moitinho de Almeida, J. A Responsabilidade Civil do Médico e o seu Seguro. Scientia Ivridica, Tomo XXI, 1972.

4. Dias Pereira, A. O consentimento informado na relação médico-paciente: estudo de direito civil. Coimbra: Coimbra Editora, 2004

5. Barendrecht, M, Jansen, C, Loos, M, Pinna, A, Cascão, R, Van Gulijk, S. Principles of European law: service contracts (PEL SC), Oxford: Oxford University Press, 2007. 
6. Lambert-Faivre, Y. Droit du dommage corporel. Systèmes d'indemnisation. Paris: Dalloz, 2004.

7. Gesetz zur Verbesserung der Rechte von Patientinnen und Patienten vom 20.2.2013, BGBI. I 2013, 277.

8. Kano, S. Comparative study of World's healthcare systems-an overview of healthcare systems in the world. Journal of Asia-Pacific Studies. n.. 17, out 2011.

9. Pearce, D, Halson, R. Damages for breach of contract: compensation, restitution, and vindication. Oxford Journal of Legal Studies. 2007; Kennedy, I, Grubb, A. Medical Law. London, Edinburgh, Dublin: Butterworths, 2000.

10. Anzivino, R. The economic loss doctrine: distinguishing economic loss from noneconomic loss. Marquette Law Review, 91 (4), 2008

11. Pichler, J. Die Patientenversicherungsrechte in Schweden, Finland und Dänemark. Rechtsentwicklungen zu einer verschulednsunabhängigen Entschädigung im Medizinbereich. Wien, Köln, Weimar: Bohlau Verlag, 1994;

12. Cascão, R. Prevention and compensation of treatment injury: a roadmap for reform. The Hague: Boom Juridische Uitgevers, 2005;

13. R. 1972: para além da culpa no ressarcimento do dano médico. Boletim da Faculdade de Direito. Vol. LXXXVII, Coimbra: 2011

14. Figueiredo Dias, J, Sinde Monteiro, J. Responsabilidade médica na Europa Ocidental. Considerações de lege ferenda. Scientia Ivridica, Tomo XXXIII, 1984

15. Hellner, J. Sweden. Medical responsibility in Western Europe. Berlin, Heidelberg, New York, Tokyo: Springer, 1985.

16. Almeida Costa, M. Direito das Obrigações. Coimbra: 4. ${ }^{\text {a }}$ Ed. 1984.

17. Antunes Varela, J. Das obrigações em geral, vol. II. Coimbra: Almedina: 7.ㄹ Ed: 1997.

18. Pinto Oliveira, N. Responsabilidade civil em instituições privadas de saúde. Responsabilidade civil dos médicos. Coimbra: Coimbra Editora, 2005.

19. Cascão, R. O dever de documentação do prestador de cuidados de saúde e a responsabilidade civil. Lex medicinae, revista portuguesa de direito da saúde, Ano 4, n. 8 , 2007, p. 34

20. Vaz Serra, A. Responsabilidade civil contratual e responsabilidade extracontratual. Boletim do Ministério da Justiça. n. $\stackrel{0}{85}, 2004$.

21. Cortez, M., Responsabilidade civil das instituições públicas de saúde. Responsabilidade civil dos médicos., Coimbra: Coimbra Editora, 2005. 
22. Figueiredo Dias, J, Sinde Monteiro, J. Responsabilidade médica na Europa Ocidental. Considerações de lege ferenda. Scientia Ivridica, Tomo XXXIII, 1984

23. Gomes, C., Serrão, T. Direito da responsabilidade civil extracontratual das entidades públicas. Anotações de jurisprudência. Lisboa, ICGP/FDUL, 2013.

24. Atiyah, F., The damages lottery, Oxford: Hart Publishing, 1997.

Recebido em: 19/9/2016

Aprovado em: 29/9/2016

\section{Como citar este artigo:}

Cascão RMPP. A responsabilidade civil contratual na prestação de cuidados de saúde em Portugal e Macau. Revista Cadernos Ibero-Americanos de Direito Sanitário. 2016 jul./set, 5(3):104-118 